\title{
HOMOCYSTEINE, PYRIDOXINE, FOLATE AND VITAMIN B12 LEVELS IN CHILDREN WITH ATTENTION DEFICIT HYPERACTIVITY DISORDER
}

\author{
Hatice Altun ${ }^{1}$, Nilfer Şahin ${ }^{2}$, Ergül Belge Kurutaș ${ }^{3}$ \& Olcay Güngör ${ }^{4}$ \\ ${ }^{I}$ Department of Child and Adolescent Psychiatry, Faculty of Medicine, \\ Kahramanmaras Sutcu Imam University, Kahramanmaras, Turkey \\ ${ }^{2}$ Department of Child and Adolescent Psychiatry, Faculty of Medicine, Muğla Sttkı Koçman University, Muğla, Turkey \\ ${ }^{3}$ Department of Biochemistry, Faculty of Medicine, Kahramanmaras Sutcu Imam University, Kahramanmaras, Turkey \\ ${ }^{4}$ Department of Pediatric Neurology, Faculty of Medicine, \\ Kahramanmaras Sutcu Imam University, Kahramanmaras, Turkey
}

received: 5.10.2017;

revised: 19.12.2017;

accepted: 23.1 .2018

\section{SUMMARY}

Background: In our study, we aimed to evaluate the serum homocysteine levels, pyridoxine, folate and vitamin B12 levels in children with attention deficit hyperactivity disorders (ADHD).

Subjects and methods: This study included 30 newly diagnosed drug-naive children with ADHD (23 males and 7 female, mean age $9.3 \pm 1.8$ years) and 30 sex-and age matched healthy controls. The diagnosis of ADHD was made according to DSM-V criteria. Children and adolescents were administered the Schedule for Affective Disorders and Schizophrenia for School Aged Children, Present and Lifetime Version, the Conners' Parent Rating Scale-Revised, Long Form, the Conners' Teacher Rating Scale and the Wechsler Intelligence Scale for Children Revised (WISC-R) for all participants. Homocysteine, pyridoxine, folate and vitamin B12 levels were measured with enzyme-linked immunosorbent assay.

Results: Homocysteine, pyridoxine, folate and vitamin 12 levels were significantly lower in children with ADHD compared with their controls $(p<0.05)$. A positive significant correlation was observed between the all WISC-R scores and vitamin B12 level in patients $(r=0.408, p=0.025)$.

Conclusions: The results obtained in this study showed that reduced homocysteine, pyridoxine, folate and vitamin B12 levels could be a risk factor in the etiology of $A D H D$.

Key words: homocysteine - pyridoxine - folate - vitamin B12 - attention deficit hyperactivity disorders - children

$* * * * *$

\section{INTRODUCTION}

Attention Deficit Hyperactivity Disorder (ADHD) is a widespread childhood neurobehavioural disorder, characterised by symptoms of inattention, impulsivity and hyperactivity, which can affect the academic, social and emotional life of a child in many aspects. ADHD has a pooled prevalence rate of $7.2 \%$ in the child and adolescent population (Association 2013, Hodgkins et al. 2013, Thomas et al. 2015). The etiology of ADHD is complex and not yet fully underestood but the findings support the hypotheses that it is multifactorial. Neurochemical, neuroanatomic, genetic and environmental factors are thought to play a role in the etiology (Sciberras et al. 2017, Swanson et al. 2007).

Homocysteine is an essential amino acid produced during the metabolism of methionine, which has several important roles in human physiology. Homocysteine metabolism is associated with pyridoxine, folate and vitamin B12 levels (Brosnan et al. 2004). Under normal conditions, there is a strict balance between homocysteine production and metabolism. Homocysteine in the body, is metabolised using either the trans-sulfuration pathways which requires pyridoxine as a cofactor, or the remethylation pathways which requires folate and Vita- min B12 together as a cofactor. Pyridoxine, folate and vitamin B12 deficiencies, and mutations in genes coding for methylenetetrahydrofolate reductase (MTHFR), cystathionine $\beta$-synthase (CBS) and methionine synthase enzymes cause homocysteine metabolic disorders and an increase in homocysteine in human tissues, known as hyperhomocysteinemia (Kałużna-Czaplińska et al. 2013, Malinowska et al. 2012, Perła-Kaján et al. 2007). Some studies have shown a relationship between folate, vitamin B12 and homocysteine and various psychiatric diseases such as cognitive disorders, neurodegenerative diseases, autism spectrum disorder, schizophrenia, affective disorder and depression (Bottiglieri et al. 2000, Ezzaher et al. 2011, Kale et al. 2010, Kałużna-Czaplińska et al. 2011, Kim \& Lee 2014, Mikkelsen et al. 2016, Stanger et al. 2009).

These observations can be explained by the important role of pyridoxine, folate, vitamin B12, and homocysteine in the carbon transfer metabolism that is necessary for the production of serotonin, other monamine neurotransmitters and catecholamines (Bottiglieri 1996). Previous studies have shown that through various molecular mechanisms, hyperhomocysteinemia is toxic for the brain (Beard et al. 2011, Ho et al. 2002, Kruman et al. 2000). However, these mechanisms are still a matter of debate. 
To the best of our knowledge, there has been no study which has shown a potential relationship between serum homocysteine, pyridoxine, folate and vitamin B12 levels and ADHD in children. In a previous study, homocysteine and oxidative stress were evaluated in adult ADHD patients and it was reported that compared to the control group, homocysteine levels were low, the folate level was high and Vitamin B12 level was normal in the adult ADHD patients (Karababa et al. 2017).

The aim of the current study was to evaluate whether or not there was a relationship between homocysteine, pyridoxine, folate and vitamin B12 levels and ADHD in children.

\section{SUBJECTS AND METHODS}

\section{Participants}

The study included 30 newly diagnosed drug-naive children with ADHD aged 6-15 years and a control group of 30 age and gender-matched healthy children. The ADHD diagnosis of the patients was made according to the DSM-V criteria. The Turkish version of the Schedule for Affective Disorders and Schizophrenia for School Aged Children, Present and Lifetime Version (KSADS-PL) was applied to all the children by one of the researchers. The K-SADS-PL is a semi-structured interview form which is used to determine present and lifetime psychopathologies in children and adolescents (Kaufman et al. 1997). The K-SADS-PL was applied taking into account the DSM-IV diagnostic criteria. Validity and reliability studies of the scale have been conducted for a Turkish population (Gökler et al. 2004). The parents of the children completed the Conners' Parent Rating Scale-Revised, Long Form and teachers completed the Conners Teacher Rating Scale. The validity of these forms was tested by Dereboy et al. (2006). Parents and teachers also completed the Turgay DSMIV-based Child and Adolescent Behavior Disorders Screening and Rating Scale. The reliability and validity testing of the scale was made by Ercan et al. (2001). The Wechsler Intelligence Scale for Children-Revised (WISC-R) was used for evaluation of the IQ of patients. Exclusion criteria were any concomitant psychiatric disease, chronic metabolic, endocrine, gastroenterological or neurological disease, malnutrition and obesity, the presence of infection, those taking vitamin or mineral support, any medication such as steroids or anti-epileptic drugs, or those with any substance addiction.

The control group was formed of the children of healthcare personnel at the hospital where the study was conducted or of patients presenting at the hospital for routine health examinations. The families were given information about the study and children who were willing to participate and were age and gender-matched to the study group were included. A psychiatric examination was made of the control group subjects and the K-SADS-PL, the Conners' Parent Rating Scale-Revised, Long Form and teachers completed the Conners Teacher
Rating Scale, the Turgay DSM-IV-based Child and Adolescent Behavior Disorders Screening and Rating Scale and WISCR were administered. Children were excluded from the control group if they had any psychiatric disorders, chronic medical disease, malnutrition and obesity, were taking any medication, vitaminmineral support or substances, or if any emotional disorder diagnosis was made with the semi-structured diagnosis interview. The study was approved by the scientific research ethical committee of Sutcu Imam University, Medical Faculty, Kahramanmaras (no:12, dated 19/10/2015), Turkey and a detailed signed informed consent was obtained from the parent of each child included in the study.

\section{Biochemical parameter measurement \\ Blood sampling}

Blood samples were taken from the study participants between 08.00 and 11.00. After separation from the serum, the samples were stored at $-20^{\circ} \mathrm{C}$ in the Biochemistry Dept until analysis. In our study, the serum levels of homocysteine, pyridoxine, folate and vitamin B 12 were measured by a quantitative sandwich enzyme immunoassay technique (ELISA) using a commercial kit (AX51301 IBL International, Hamburg, Germany, CEA916Ge Cloud-Clone Corp., Houston, USA, CEA610Ge Cloud-Clone Corp., Houston, USA CEA924Ge Cloud-Clone Corp., Houston, USA, respectively) according to the manufac turer's instructions.

\section{Statistical Analysis}

Data obtained in the study were analysed with Windows SPSS 22 software. The study data were summarised using descriptive statistics (number, percentage). The patient and control groups were compared using the using the chi-square test for categorial variables and the Student's t-test for continuous data. Correlations between the clinical variables were analysed with the Pearson's correlation test. A value of $\mathrm{p}<0.05$ was accepted as statistically significant.

\section{RESULTS}

The study group of children with ADHD comprised 23 males and 7 females with a mean age of $9.33 \pm 1.8$. The control group comprised 21 males and 9 females with a mean age of $9.46 \pm 1.87$ years (range, 6-15 years). No statistically significant difference was determined between the groups in respect of age, gender, all WISCR scores ( $\mathrm{p}>0.05$ for all). (Table 1$)$.

The mean serum homocysteine level of the ADHD patients was found to be statistically significantly lower compared to that of the control group $(5.29 \pm 0.73$ and $6.54 \pm 2.17(\mu \mathrm{mol} / \mathrm{L})($ mean $\pm \mathrm{sd})$, respectively $\mathrm{p}=0.004)$. The levels of pyridoxine, folate and vitamin B12 were determined to be statistically significantly lower in the ADHD group compared to the levels of the control group 
Table 1. Characteristics of patients and healthy controls

\begin{tabular}{lccc}
\hline & ADHD $(\mathrm{n}=30)$ & Controls $(\mathrm{n}=30)$ & $p$ \\
\hline Gender $($ male/female) & $23 / 7$ & $21 / 9$ & 0.559 \\
Age, years, $($ mean \pm sd) & $9.33 \pm 1.84$ & $9.46 \pm 1.87$ & 0.782 \\
WISC-R scores & & & 0.483 \\
Verbal & $100.03 \pm 6.24$ & $101.36 \pm 8.23$ & 0.079 \\
Performance & $99.66 \pm 6.81$ & $103.66 \pm 9.39$ & 0.201 \\
Total & $99.93 \pm 5.94$ & $102.20 \pm 7.52$ & \\
\hline
\end{tabular}

ADHD - Attention deficit hyperactivity disorder; sd - standard deviation; WISC-R - Wechsler intelligence scale for children-revised; statistically significant at $\mathrm{p}<0.05$

Table 2. Laboratory results of patients and healthy controls

\begin{tabular}{|c|c|c|c|}
\hline & $\begin{array}{c}\operatorname{ADHD}(n=30) \\
\text { mean } \pm \text { sd }\end{array}$ & $\begin{array}{c}\text { Controls }(\mathrm{n}=30) \\
\text { mean } \pm \text { sd }\end{array}$ & $p$ \\
\hline Homocysteine $(\mu \mathrm{mol} / \mathrm{L})$ & $5.29 \pm 0.73 *$ & $6.54 \pm 2.17$ & 0.004 \\
\hline Piridoxine (ng/mL) & $45.41 \pm 5.64 *$ & $53.87 \pm 8.50$ & $<0.001$ \\
\hline Folate $(\mathrm{pg} / \mathrm{mL})$ & $158.90 \pm 20.22^{*}$ & $169.13 \pm 16.98$ & 0.038 \\
\hline Vitamin B12 (pg/mL) & $259.75 \pm 44.40^{*}$ & $388.64 \pm 73.11$ & $<0.001$ \\
\hline
\end{tabular}

ADHD - Attention deficit hyperactivity disorder; sd - standard deviation; statistically significant at $\mathrm{p}<0.05$;

${ }^{*}$ Lower than those of controls

Table 3. Correlations of homocysteine, piridoxine, folate and vitamin B12 results with age and WISC-R scores of ADHD patients

\begin{tabular}{|c|c|c|c|c|}
\hline & Homocysteine & Piridoxine & Folate & Vitamin B12 \\
\hline \multicolumn{5}{|c|}{ Age } \\
\hline $\mathrm{r}$ & -0.237 & 0.017 & 0.005 & -0.145 \\
\hline $\mathrm{p}$ & 0.208 & 0.929 & 0.981 & 0.446 \\
\hline \multicolumn{5}{|c|}{ WISC-R Verbal } \\
\hline $\mathrm{r}$ & 0.259 & -0.017 & -0.008 & $0.409 *$ \\
\hline $\mathrm{p}$ & 0.167 & 0.931 & 0.968 & 0.025 \\
\hline \multicolumn{5}{|c|}{ WISC-R Performance } \\
\hline $\mathrm{r}$ & 0.015 & 0.214 & 0.056 & $0.396^{*}$ \\
\hline $\mathrm{p}$ & 0.936 & 0.257 & 0.767 & 0.030 \\
\hline \multicolumn{5}{|c|}{ WISC-R Total } \\
\hline $\mathrm{r}$ & 0.124 & 0.126 & -0.007 & $0.408 *$ \\
\hline $\mathrm{P}$ & 0.514 & 0.505 & 0.969 & 0.025 \\
\hline
\end{tabular}

Pearson correlations, ADHD - Attention deficit hyperactivity disorder; WISC- R, Wechsler intelligence scale for children-revised

$(45.41 \pm 5.64(\mathrm{ng} / \mathrm{mL})$ vs $53.87 \pm 8.50(\mathrm{ng} / \mathrm{mL}),(\mathrm{p}<0.001)$; $158.90 \pm 20.22(\mathrm{pg} / \mathrm{mL})$ vs $169.13 \pm 16.98 \quad(\mathrm{pg} / \mathrm{mL})$, $(\mathrm{p}=0.038) ; 259.75 \pm 44.40 \quad(\mathrm{pg} / \mathrm{mL}) \quad$ vs $388.64 \pm 73.11$ $(\mathrm{pg} / \mathrm{mL})($ mean $\pm \mathrm{sd}),(\mathrm{p}<0.001)$, respectively) (Table 2$)$.

According to the Pearson Correlation analysis, a positive correlation was determined between the all WISC$\mathrm{R}$ scores and vitamin B12 in ADHD patients. No correlation was determined between age and homocysteine, pyridoxine, folate, Vitamin B12 levels in children with ADHD (Table 3). No correlation was also determined between the points of the Conners Parent and Conners Teacher Rating Scale and homocysteine, pyridoxine, folate and Vitamin B12 levels in ADHD ( $p>0.05$ for all).

\section{DISCUSSION}

In this study, the serum homocysteine level of ADHD children was found to be statistically significantly lower than that of the control group. To the best of our knowledge, this is the first study to have evaluated the relationship between the serum homocysteine level and ADHD in children.

Although the mechanism of homocysteine in the development of psychiatric disease is not fully known, it is thought that a high homocysteine concentration causes excitotoxicity by activating N-methyl-D-aspartate receptors and increases oxidative stress, thereby causing psychiatric diseases (Beard et al. 2011, Ho et al. 2002, Kruman et al. 2000). Previous studies have reported that a high homocysteine level has a role in several neurodegenerative diseases, cognitive disorders and psychiatric diseases (Bottiglieri et al. 2000, Kałużna-Czaplińska et al. 2011, Kim \& Lee 2014, Mattson \& Shea 2003, Stanger et al. 2009). Although studies have reported a high level of homocysteine in schizophrenia, there are also studies that do not support this finding (Kale et al. 2010, Miodownik et al. 2007, Muntjewerff et al. 2003). Karababa et al. evaluated homocysteine levels in adult 
ADHD patients and it was reported that compared to the control group, homocysteine levels were low, the folate level was high and vitamin B12 level was normal in in the ADHD patients (Karababa et al. 2017). Similarly in the current study, the homocysteine level was seen to be low in children with ADHD. Although a high homocysteine level is thought to be related to several diseases, a low homocysteine level has been reported to create a risk for some diseases. For example, a strong relationship has been shown between low homocysteine and periphereal neuropathy (Cullen et al. 2012). Moreover, a low homocysteine level could be an indicator of excessive transformation to cystatin in the trans-sulfuration pathways for glutathione, taurin and sulphate production. For example, in individuals with Down's syndrome, as there is greater transformation of homocysteine to cysteine associated with excessive activation in the CBS enzyme which functions in the tran-sulphuration pathway, the serum homocysteine level has been reported to be low (Gane \& Bhat 2014). Homocysteine is thought to be a storage molecule for sulphur and a transfer molecule for methyl metabolism. As homocysteine is a normal mediating substance for the transformation of methionine to cysteine and thereby has a role in glutathione, taurin and sulphate production, hypohomocysteine creates a risk for the body because hypohomocysteine causes a reduction in cysteine. Reduced cysteine limits the production of sulphate, taurin and glutathione (necessary for the glutathione mechanism which is an important antioxidant system of the body). Individuals with low homocysteine have a limited capacity to respond to oxidative stress and exposure to certain toxins (Vitvitsky et al. 2003). It was shown that a reduction in glutathione is related to diseases that affect almost all large organ systems (Lang et al. 2000, Lord \& Fitzgerald 2006). In addition, any condition which increases oxidative stress in body has the tendency to increase the demand for hepatic glutathione production. Thus, oxidative stress leads to homocysteine glutathione synthesis causing a fall in plasma homocysteine levels which are critical for the potential total body glutathione status. This means that a low homocysteine level could restrict the amount of glutathione which could be produced as a response to oxidative stress (Pizzorno 2014). Therefore, low levels of homocysteine levels caused by increases oxidative stress can be important in the etiology of children with ADHD. In line with this finding, although a high homocysteine level has been reported to be a risk factor in neurodegenerative diseases and psychiatric diseases such as schizophrenia, ASD, it is also thought that a low homocysteine level could be a risk factor for ADHD. However, the mechanism of this is not clear. As this is the first study to have shown a reduced homocysteine level in children with ADHD, there is a need for further studies to support this finding.

In this study, the pyridoxine, folate and Vitamin B12 levels of the ADHD group were found to be low compared to those of the control group. Optimal develop- ment and functioning of the immature central nervous system (CNS) is dependent on a sufficient amount of pyridoxine (Bowling 2011, Georgieff et al. 2015). Maternal pyridoxine deficiency can cause motor and behavioural abnormalities such as hyperactivity, seizures, ataxia and neuropsychiatric disorders (Guilarte et al. 1991). The primary symptoms of pyridoxine deficiency are neurological such as depression, reduced cognition, dementia and autonomic dysfunction (Stover \& Field 2015, Dakshinamurti \& Dakshinamurti 2013). Furthermore, it is necessary for the synthesis and metabolism of neurotransmitters such as glutamate, noradrenalin, serotonin, gamma-aminobutyric acid (GABA) and dopamine in the CNS (Bowling 2011, Stover \& Field 2015, Dakshinamurti \& Dakshinamurti 2013). Therefore, because of the biochemical disorders (catecholamine and serotonin deficiency, glutamate/GABA imbalance and excessive plasma tryptophan) that emerge in ADHD, it has been reported that it could be a disease related to pyridoxine (Dolina et al. 2014). In addition, decreased methylation of dopamine receptors and membrane phospholipids could contribute to attention deficit disorder (Kuznetsova \& Deth 2008). In the current study, the low pyridoxine level in the ADHD group suggests that there could be an effect in the formation of ADHD through the effect on neurotransmitters.

Folate have a role in important biochemical events such as primarily purine and pyrimidine and the metabolism of homocysteine and methionine amino acids. They also affect neural stem cell proliferation and differentiation, reduce apoptosis, and alter DNA biosynthesis. Therefore, folate is an esential substance in tissues in which DNA construction and destruction is rapid, such as in embryo development, gastrointestinal tract mucosa and hematopoietic tissues (Bailey 2007, Mattson \& Shea 2003, Miller 2008). In addition, the effective functioning of the folate cycle is necessary for the synthesis and regeneration of tetrahydrobiopterin which is a cofactor necessary for enzymes that transforming amino acids to nitric oxide and monamine neurotransmitters (serotonin, melatonin, dopamine, noradrenalin, adrenalin) (Kennedy 2016). Previous studies have reported that folate deficiency has a role in the etiology of neurodegenerative diseases such as Alzheimer's and Parkinson's disease as it causes an increase in the homocysteine level (Mattson \& Shea 2003). Studies conducted on the relationship between ADHD and folate and folate metabolism have focussed on symptoms of folate deficiency in the antenatal period which will be observed in childhood (Julvez et al. 2009, Schlotz et al. 2010). Developmental delays, cognitive impairment and reduced memory function have been shown to be related to cerebral folate deficiency of abnormal folate transfer to the fetal CNS (Mattson \& Shea 2003, Moretti et al. 2008, Schlotz et al. 2010), and better cognitive performance (de Lau et al. 2007) has been related to higher plasma folate. Maternal folate deficiency in the gestational period has been related to hyperactivity in childhood (Schlotz et al. 2010). There 
are very few studies that have examined the relationship between folate and ADHD in children. It is shown that a low folate level, independent of attention deficit type, age and gender, is strongly related to ADHD (Krull et al. 2008). In a study investigating the role of the folate homocysteine metabolic pathway in the etiology of ADHD, it was also shown that folate homocysteine pathway gene variants could affect the etiology of ADHD through mild hyperhomocysteinemia and vitamin B12 deficiency (Saha et al. 2017). Due to the supplementary roles of folate and Vitamin B12 in folate and methionine cycles, they are inseparably associated with each other. In fact, Vitamin B12 deficiency causes a functional folate deficiency when folate is held in methyltetrahydrofolate form (Reynolds 2006). Vitamin B12 is necessary for brain development, neural myelineation and cognitive function. Vitamin B12 deficiency in pregnancy and early childhood has been related to negative results in child health, primarily cognitive development disorders. However, the underlying mechanisms have not yet been clarified (Venkatramanan et al. 2016). In contrast, a review by Van de Rest et al. found a very limited number of studies that had examined the relationship between maternal vitamin B12 level and cognition and it was reported that as the results were inconsistent, there was thought to be a need for more research in this area (Van De Rest et al. 2012). Vitamin $\mathrm{B} 12$ is known to have a role in the prevention of disorders of CNS development, mood disorders and dementia disorders (Reynolds 2006). In a recent study is shown that children with ADHD compared to healthy controls have lower vitamin B12 level (Bala et al. 2016). In the current study, that the level of serum vitamin B12 was found to be low in the ADHD group compared to the control group support the findings of previous study.

Pyridoxine, folate and vitamin B12 are responsible for the acquisition of methyl groups, which are necessary for DNA and protein synthesis, and function as a cofactor in the one carbon metabolism formed from folate and methionine-homocysteine cycles. One carbon metabolism is very important in phospholipid synthesis, protein function, neurotransmitter synthesis and the regulation of DNA/RNA synthesis and metabolism. Therefore, pyridoxine, folate and vitamin B12 undertake significant functions in brain development, differentiation, maintenance and function (Mitchell et al. 2014, Reynolds 2006, Stover \& Field 2015). In addition, it is known that one carbon metabolism affects epigenetic modifications which cause long-term changes affecting the brain memory, learning, cognition and behaviours (Schaevitz et al. 2014). A disruption in this metabolism has been shown in psychatric diseases such as schizophrenia, bipolar disorder, ASD and depression (Sugden 2006). In the current study, it is thought that deficiency of pyridoxine, folate and B12 in children with ADHD may play a role in the etiology of ADHD through the impairment of the one carbon metabolism. However, further research is needed to clarify the pathogenesis of the relationship between one carbon metabolism and ADHD.
A genetic defect may be a reason for an impairment in pyridoxine, folate and Vitamin B12 metabolism or malnutrition of these vitamins may cause an impairment in homocysteine metabolism. However, in the current study, despite the reduction seen in pyridoxine, folate and vitamin B12 levels in the ADHD group, no increase was observed in the homocysteine level. This indicates that different mechanisms other than these vitamins could have a role in homocysteine metabolism.

In our study, there was no correlation between age, Conner's parent and teacher rating scale scores and intelligence level and pyridoxine, folate and vitamin B12 levels except positive correlations between intelligence level and vitamin B12. These results may indicate that vitamin B12 level may also be a possible risk factor for cognitive problems in children with ADHD.

To the best of our knowledge, this is the first study to have analysed the relationship between homocysteine, pyridoxine, folate and vitamin B12 in ADHD children. However, there were some limitations to this study, the most important of which were the small size of the sample and that there was no investigation of a possible genetic basis for the differences in the serum homocysteine and folate levels such as gene polymorphisms associated with MTHFR and other homocysteine metabolism.

\section{CONCLUSION}

Unlike other psychiatric diseases which are related to a high homocysteine level, a low homocysteine level could be considered a risk factor in the etiology of ADHD. Furthermore, the results obtained in this study showed that reduced pyridoxine, folate and vitamin B12 levels could be a risk factor for ADHD independent of the homocysteine levels. Pyridoxine, folate and vitamin B12 deficiency which is one of the preventable and treatable medical condition, could be given attention especially in ADHD patients. It can be useful to investigate pyridoxine, folate and vitamin B12 deficiency for patients with an ADHD diagnosis and treatment process. However, there is a need for further research verifying whether or not the compensation of folate, pyridoxine and vitamin B12 deficiencies in ADHD children will lead to behavioural and functional benefits and of the effects on homocysteine metabolism in ADHD.

\section{Contribution of individual authors:}

Hatice Altun: study design, data collection, analysis and interpretation of data, literature review, statistical analysis, manuscript preparation, approval of the final version;

Nilfer Şahin: study design, analysis and interpretation of data, statistical analysis, manuscript preparation, approval of the final version;

Ergül Belge Kurutaş: study design, analysis and interpretation of data, approval of the final version:

Olcay Güngör: data collection, analysis and interpretation of data, approval of the final version 


\section{Acknowledgements: None.}

\section{Conflict of interest: None to declare.}

\section{References}

1. Association AP: Diagnostic and statistical manual of mental disorders (DSM-5®). American Psychiatric Pub, 2013

2. Bailey LB: Folic acid. In Handbook of Vitamins, 4th ed.; Zempleni J, Rucker RB, McCormick DB, Suttie JW. Eds.; CRC Press: Boca Raton, FL, USA, 2007

3. Bala KA, Doğan M, Kaba S, Mutluer T, Aslan O \& Doğan SZ: Hormone disorder and vitamin deficiency in attention deficit hyperactivity disorder (ADHD) and autism spectrum disorders (ASDs). J Pediatr Endocrinol Metab 2016; 29:1077-82

4. Beard RS, Reynolds JJ \& Bearden SE: Hyperhomocysteinemia increases permeability of the blood-brain barrier by NMDA receptor-dependent regulation of adherens and tight junctions. Blood 2011; 118:2007-14

5. Bottiglieri T: Folate, vitamin B12, and neuropsychiatric disorders. Nutr Rev 1996; 54:382-90

6. Bottiglieri T, Laundy M, Crellin R, Toone BK, Carney MW \& Reynolds EH: Homocysteine, folate, methylation, and monoamine metabolism in depression. $J$ Neurol Neurosurg Psychiatry 2000; 69:228-32

7. Bowling FG: Pyridoxine supply in human development. Paper presented at: Semin Cell Dev Biol 2011; 22:611-8

8. Brosnan JT, Jacobs RL, Stead LM \& Brosnan ME: Methylation demand: a key determinant of homocysteine metabolism. Acta Biochim Pol 2004; 51:405-14

9. Cullen CE, Carter GT, Weiss MD, Grant PA \& Saperstein DS: Hypohomocysteinemia: a potentially treatable cause of peripheral neuropathology? Phys Med Rehabil Clin N Am 2012; 23:59-65

10. De Lau LM, Refsum H, Smith AD, Johnston C \& Breteler MM: Plasma folate concentration and cognitive performance: Rotterdam Scan Study. Am J Clin Nutr 2007; 86:728-34

11. Dakshinamurti $S \&$ \&akshinamurti K: Vitamin B6. In Handbook of Vitamins, 5th ed.; Zempleni J, Suttie JW, Gregory JF, Stover PJ. Eds.; CRC Press: Boca Raton, FL, USA, 2013

12. Dereboy C, Senol S, Sener $S$ \& Dereboy F: Validation of the Turkish versions of the short-form Conners' teacher and parent rating scales. Turk Psikiyatri Derg 2006; 18:48-58

13. Dolina S, Margalit D, Malitsky $S$ \& Rabinkov A: Attention-deficit hyperactivity disorder (ADHD) as a pyridoxine-dependent condition: Urinary diagnostic biomarkers. Med hypotheses 2014; 82:111-6

14. Ercan E, Amado S, Somer O \& Çıkoğlu S: Development of a test battery for the assessment of attention deficit hyperactivity disorder. Turk $J$ Child and Adolesc Ment Health 2001; 8:132-44

15. Ezzaher A, Mouhamed DH, Mechri A, Omezzine A, Neffati F, Douki $W$ et al.: Hyperhomocysteinemia in Tunisian bipolar I patients. Psychiatry Clin Neurosci. 2011; 65:664-71

16. Gane $B \&$ Bhat V: Folate and Homocysteine metabolism in Indian children with Down syndrome. Curr Pediatr 2014: 18:11-4
17. Georgieff MK, Brunette KE \& Tran PV: Early life nutrition and neural plasticity. Dev Psychopathol 2015; 27:411-23

18. Gökler B, Ünal F, Pehlivantürk B, Kültür EÇ, Akdemir D \& Taner Y: Reliability and validity of schedule for affective disorders and schizophrenia for school age children-present and lifetime version-Turkish version ( $K$ SADS-PL-T). Turk $J$ Child and Adolesc Ment Health 2004; 11:109-16

19. Guilarte TR, Miceli RC \& Moran TH: Developmental effects of vitamin B-6 restriction on the locomotor behavior of rats. Brain Res Bull 1991; 26:857-61

20. Ho PI, Ortiz D, Rogers E \& Shea TB: Multiple aspects of homocysteine neurotoxicity: glutamate excitotoxicity, kinase hyperactivation and DNA damage. J Neurosci Res 2002; 70:694-702

21. Hodgkins P, Setyawan J, Mitra D, Davis K, Quintero J, Fridman Met al.: Management of ADHD in children across Europe: patient demographics, physician characteristics and treatment patterns. Eur J Pediatr 2013; 172:895-906

22. Julvez J, Fortuny J, Mendez M, Torrent M, Ribas Fitó $N$ \& Sunyer J: Maternal use of folic acid supplements during pregnancy and four-year-old neurodevelopment in a population-based birth cohort. Paediatr Perinat Epidemiol 2009; 23:99-206

23. Kale A, Naphade N, Sapkale S, Kamaraju M, Pillai A, Joshi $S$ et al.: Reduced folic acid, vitamin $B 12$ and docosahexaenoic acid and increased homocysteine and cortisol in never-medicated schizophrenia patients: implications for altered one-carbon metabolism. Psychiatry Res 2010; 175:47-53

24. Kałużna-Czaplińska J, Michalska $M$ \& Rynkowski J: Homocysteine level in urine of autistic and healthy children. Acta Biochim Pol 2011; 58:31-4

25. Katużna-Czaplińska J, Żurawicz E, Michalska $M$ \& Rynkowski J: A focus on homocysteine in autism. Acta Biochim Pol 2013; 60:137-42

26. Karababa IF, Savas SN, Selek S, Cicek E, Cicek EI, Asoglu $M$ et al.: Homocysteine levels and oxidative stress parameters in patients with adult ADHD. J Atten Disord 2017; 21:487-93

27. Kaufman J, Birmaher B, Brent D, Rao U, Flynn C, Moreci $P$ et al.: Schedule for affective disorders and schizophrenia for school-age children-present and lifetime version (K-SADS-PL): initial reliability and validity data. J Am Acad Child Adolesc Psychiatry 1997; 36:980-8

28. Kim H \& Lee KJ: Serum homocysteine levels are correlated with behavioral and psychological symptoms of Alzheimer's disease. Neuropsychiatr Dis Treat 2014; 10:1887-96

29. Kennedy DO: B vitamins and the brain: mechanisms, dose and efficacy - a review. Nutrients 2016; 8:68

30. Krull KR, Brouwers P, Jain N, Zhang L, Bomgaars L, Dreyer $Z$ et al.: Folate pathway genetic polymorphisms are related to attention disorders in childhood leukemia survivors. J Pediatr 2008; 152:101-5

31. Kruman II, Culmsee C, Chan SL, Kruman Y, Guo Z, Penix $L$ et al.: Homocysteine elicits a DNA damage response in neurons that promotes apoptosis and hypersensitivity to excitotoxicity. J Neurosci 2000; 20:6920-6

32. Kuznetsova $A Y \&$ Deth RC: A model for modulation of neuronal synchronization by $D 4$ dopamine receptormediated phospholipid methylation. J Comput Neurosci 2008; 24:314-29 
33. Lang CA, Mills BJ, Mastropaolo W \& Liu MC: Blood glutathione decreases in chronic diseases. J Lab Clin Med 2000; 135:402-5

34. Lord RS \& Fitzgerald K: Significance of Low Plasma Homocysteine, 2006

35. Malinowska J, Kolodziejczyk $J$ \& Olas B: The disturbance of hemostasis induced by hyperhomocysteinemia; the role of antioxidants. Acta Biochim Pol 2012; 59:185-194

36. Mattson MP \& Shea TB: Folate and homocysteine metabolism in neural plasticity and neurodegenerative disorders. Trends Neurosci 2003; 26:137-46

37. Mikkelsen K, Stojanovska L, Tangalakis K, Bosevski M \& Apostolopoulos $V$ : Cognitive decline: a vitamin $B$ perspective. Maturitas 2016; 93:108-13

38. Miller AL: The methylation, neurotransmitter, and antioxidant connections between folate and depression. Altern Med Rev 2008; 13:216-27

39. Miodownik $C$, Lerner $V$, Vishne T, Sela B-A \& Levine J: High-dose vitamin B6 decreases homocysteine serum levels in patients with schizophrenia and schizoaffective disorders: a preliminary study. Clin Neuropharmacol 2007; 30:13-7

40. Mitchell ES, Conus $N$ \& Kaput J: B vitamin polymorphisms and behavior: Evidence of associations with neurodevelopment, depression, schizophrenia, bipolar disorder and cognitive decline. Neurosci Biobehav Rev 2014: 47:307-20

41. Moretti P, Peters SU, Del Gaudio D, Sahoo T, Hyland K, Bottiglieri $T$ et al.: Brief report: autistic symptoms, developmental regression, mental retardation, epilepsy, and dyskinesias in CNS folate deficiency. $J$ Autism Dev Disord 2008; 38:1170-7

42. Muntjewerff $J-W$, van der Put N, Eskes T, Ellenbroek B, Steegers E, Blom H et al.: Homocysteine metabolism and $B$-vitamins in schizophrenic patients: low plasma folate as a possible independent risk factor for schizophrenia. Psychiatry Res 2003; 121:1-9

43. Perła-Kaján J, Twardowski T \& Jakubowski H: Mechanisms of homocysteine toxicity in humans. Amino acids 2007; 32:561-72

44. Pizzorno J: Homocysteine: Friend or Foe? Integr Med 2014; 13:8-14

45. Reynolds E: Vitamin B12, folic acid, and the nervous system. Lancet Neurol 2006; 5:949-60
46. Saha T, Chatterjee M, Sinha S, Rajamma U \& Mukhopadhyay K: Components of the folate metabolic pathway and ADHD core traits: an exploration in eastern Indian probands. J Hum Genet 2017; 62:687-95

47. Schaevitz L, Berger-Sweeney J \& Ricceri L: One-carbon metabolism in neurodevelopmental disorders: using broadbased nutraceutics to treat cognitive deficits in complex spectrum disorders. Neurosci Biobehav Rev 2014; 46:270-84

48. Schlotz W, Jones A, Phillips DI, Gale CR, Robinson SM \& Godfrey KM: Lower maternal folate status in early pregnancy is associated with childhood hyperactivity and peer problems in offspring. $J$ Child Psychol Psychiatry 2010; 51:594-602

49. Sciberras E, Mulraney M, Silva D \& Coghill D: Prenatal Risk Factors and the Etiology of ADHD - Review of Existing Evidence. Curr Psychiatry Rep 2017; 19:1

50. Stanger O, Fowler B, Piertzik K, Huemer M, HaschkeBecher E, Semmler A et al.: Homocysteine, folate and vitamin $B 12$ in neuropsychiatric diseases: review and treatment recommendations. Expert Rev Neurother 2009; 9:1393-412

51. Stover PJ \& Field MS: Vitamin B-6. Adv Nutr 2015; 6:132-3

52. Sugden C: One-carbon metabolism in psychiatric illness. Nutr Res Rev 2006; 19:117-36

53. Swanson JM, Kinsbourne M, Nigg J, Lanphear B, Stefanatos GA, Volkow $N$ et al.: Etiologic subtypes of attention-deficit/hyperactivity disorder: brain imaging, molecular genetic and environmental factors and the dopamine hypothesis. Neuropsychol Rev 2007; 17:39-59

54. Thomas R, Sanders S, Doust J, Beller E \& Glasziou P: Prevalence of attention-deficit/hyperactivity disorder: a systematic review and meta-analysis. Pediatrics 2015; 135:994-1001

55. Van De Rest O, Van Hooijdonk LW, Doets E, Schiepers OJ, Eilander A \& De Groot LC: B Vitamins and n-3 fatty acids for brain development and function: Review of human studies. Ann Nutr Metab 2012; 60:272-92

56. Venkatramanan S, Armata IE, Strupp BJ \& Finkelstein JL: Vitamin B-12 and cognition in children. Adv Nutr 2016; 7:879-88

57. Vitvitsky V, Mosharov E, Tritt M, Ataullakhanov $F \&$ Banerjee R: Redox regulation of homocysteine-dependent glutathione synthesis. Redox Rep 2003; 8:57-63

Correspondence:

Assist. Prof. Hatice Altun, MD

Department of Child and Adolescent Psychiatry

Faculty of Medicine, Kahramanmaras Sutcu Imam University

Kahramanmaras, Turkey

E-mail:drhaticealtun@gmail.com 